\title{
Narrativas jornalísticas sobre saúde, cuidado e risco, segundo adolescentes moradores de uma periferia do Rio de Janeiro, Brasil
}

\author{
Journalistic narratives about health, care and risk, according \\ to adolescents living on the outskirts of Rio de Janeiro, Brazil
}

Marcia Rodrigues Lisboa (https://orcid.org/0000-0002-2059-370X) ${ }^{1}$

${ }^{1}$ Laboratório de Comunicação e Saúde, Instituto de Comunicação e Informação Científica e Tecnológica em Saúde, Fundação Oswaldo Cruz. Av. Brasil 4036/512,

Manguinhos. 21040-361 Rio de Janeiro RJ Brasil.

marcia.lisboa@icict.fiocruz.br

\begin{abstract}
The scope of this article is to analyze the meanings constructed by adolescents living in Maré, in the outskirts of Rio de Janeiro, based on their access to journalistic coverage on health care and risk, available on different technological platforms and social media. The discussion stems from more comprehensive qualitative research, supported by two theoretical axes: the discursive construction of the concept of health risk in contemporary times; and the role of journalism as a prominent actor in the production and circulation of information and its approach on the subject. The main empirical research resource was discussion groups with teenagers aged between 14 and 16. This technique seeks to observe the interactive and discursive processes of the research participants. The analysis of the materials, among other findings, shows that: a) the presence of journalism in the daily lives of these young people is not without criticism of its modus operandi, irrespective of the reliability of each specific vehicle; $b$ ) the criticism extends to other actors used as sources of the articles/reports, especially when addressing issues related to conditions of social vulnerability; c) the repetition of warnings about health risks in the news has considerable potential for excess coverage and burnout.
\end{abstract}

Key words Adolescent, Risk, Journalism, Appropriation, Communication and health
Resumo $O$ objetivo deste artigo é analisar os sentidos construídos por adolescentes residentes na Maré, região periférica da cidade do Rio de Janeiro, a partir do acesso a produções jornalísticas sobre cuidado e risco à saúde disponiveis em diferentes plataformas e suportes tecnológicos. A discussão proposta origina-se de uma investigação qualitativa mais abrangente, sustentada em dois eixos teóricos: a construção discursiva do conceito de risco à saúde na contemporaneidade e a participação do jornalismo no cenário comunicacional como um ator destacado na produção de informações e de posicionamentos sobre a temática. $O$ principal recurso metodológico da pesquisa empírica foram grupos de discussão com adolescentes de 14 a 16 anos. A técnica busca observar os processos interativos e discursivos dos sujeitos de pesquisa. A análise dos materiais aponta, dentre outros achados, que: a) a presença do jornalismo no cotidiano desses jovens não se dá sem críticas ao seu modus operandi, independentemente da confiabilidade no veículo; $b$ ) a crítica se estende a outros atores acionados como fontes das matérias/ reportagens, sobretudo ao abordarem temas relacionados a condições de vulnerabilidade social; $c$ ) a repetição de alertas sobre riscos à saúde no noticiário tem grande potencial de esgotamento.

Palavras-chave Adolescente, Risco, Jornalismo, Apropriação, Comunicação e saúde 


\section{Introdução}

O estudo surge de uma inquietação acerca das formas de apropriação de narrativas jornalísticas sobre cuidado e risco à saúde por adolescentes que vivem em regiões periféricas de grandes cidades: como leem/ouvem/veem notícias, reportagens ou outros materiais jornalísticos sobre a temática? A discussão resulta de uma investigação mais ampla, de cunho qualitativo, que teve como participantes adolescentes residentes na Maré, região periférica da cidade do Rio de Janeiro. O objetivo deste artigo é analisar os sentidos construídos por eles, a partir do acesso a produções jornalísticas sobre cuidado e risco à saúde. A pesquisa apoiou-se em dois eixos teóricos: a construção discursiva do conceito de risco à saúde na contemporaneidade; e a participação do jornalismo no cenário comunicacional como um ator destacado na produção e circulação de informações e de posicionamentos sobre a temática. No que se refere ao primeiro eixo, ressaltase a centralidade adquirida pela noção de risco a partir da segunda metade do século XX; e de forma mais complexa após meados dos anos 1980, em diferentes campos do conhecimento, com múltiplas imbricações à vida cotidiana. No campo da saúde, a construção da ideia de risco alçou fundamentos epidemiológicos, sustentados no tripé regularidades, controle e prevenção, para embasar ações voltadas ao cuidado de si, o que não ocorreu sem embates no âmbito da promoção de saúde, compreendida em sua pluralidade de elaborações, nem sempre convergentes, conforme Czeresnia ${ }^{1}$.

A responsabilização individual pela saúde, tendo o cuidado da própria vida como expectativa de controle do futuro, apoia-se em receituários de estilo de vida, que incluem, por exemplo, a disseminação de informações sobre alimentação saudável, prática de esportes e outras prescrições. O cuidado crônico de $\mathrm{si}^{2}$ promove um alargamento da concepção de quem está ou não vulnerável, modificando o próprio conceito de "doença".

Neste contexto, a condição de adolescente emerge à medida que o crivo etário se apresenta como um destacado condicionante para o enquadramento de indivíduos na categoria "grupo de risco". Ainda que as classificações etárias sejam questionáveis e não se possa falar de uma adolescência apenas, uma juventude ou uma velhice, de forma deslocada da cultura e da vida cotidiana ${ }^{3}$, a amplitude adquirida pela noção de risco, em um ambiente calcado no hiperpreventivismo ${ }^{4}$, contribuiu para o reforço de uma pasteurização de gru- pos etários, ignorando a diversidade dos indivíduos que se encaixam em uma determinada faixa.

Não se trata de desconsiderar a idade como um referente importante, mas sim de relativizá-la, tendo em vista que adquire distintas valorações em diferentes sociedades e também na mesma sociedade ${ }^{5}$. A pesquisa orientou-se pelo entendimento da adolescência como um construto social, no qual se destaca seu caráter instável e plural. Portanto, não se limita a processos biológicos desencadeadores de padrões de conduta para qualquer pessoa nesse período da vida e tampouco pode ser reduzida a tipologias associadas à ideia de geração ${ }^{6}$.

O segundo eixo analítico situa o jornalismo no contexto contemporâneo de midiatização, compreendida em uma de suas facetas, como uma forma exacerbada de mediação das tecnologias de informação e comunicação que perpassa as relações sociais? ${ }^{7}$. A midiatização não se limita à produção de empresas jornalísticas, projetando-se também nos espaços de comunicação ocupados por diferentes produtores e distribuidores informacionais, sobretudo a partir da metade da primeira década deste milênio, quando a segunda geração de comunidades e serviços na web ampliou de maneira exponencial as possibilidades de produção individual ou coletiva de conteúdos de natureza e formatos distintos.

Neste cenário de múltiplos atores, a atuação do jornalismo profissional, especialmente nas grandes corporações do setor, foi tensionada por disputas discursivas que demandaram uma revisão da pactuação com seus públicos. Ainda que sob a égide da credibilidade, empresas de comunicação abriram frentes diversas em suas plataformas na internet para a incorporação de parcerias variadas, com produções de jornalistas e outros profissionais de áreas diversas, como saúde e entretenimento, em diferentes formatos.

Pensar sobre a apropriação dos adolescentes de tais produções jornalísticas implica em tomá -los como participantes do processo comunicacional, e não como receptáculos de conteúdos, passivos diante do que leem/ouvem/assistem. Apesar do desequilíbrio na distribuição informacional, do volume exacerbado de conteúdos e da velocidade em que circulam, dentre outros fatores relacionados à desigualdade no acesso às informações, são limitados os argumentos na forma da indústria cultural que negam a capacidade reflexiva dos sujeitos.

Tais modelos macroexplicativos da relação entre a sociedade e a mídia não dão conta do processo comunicacional, ao relegarem à cultu- 
ra uma posição secundária à dimensão políticoideológica e o reconhecimento de seu poder de negociação. Rejeita-se, assim, a ideia de um continuum que parta da análise das lógicas de produção e recepção para depois procurar suas relações de imbricação ou enfrentamento ${ }^{8}$.

O termo "processo" sinaliza ainda o caráter contínuo da apropriação, que não somente demanda tempo, mas pode se modificar através dele, por motivos diversos. Há na apropriação um convite à inserção do sujeito. Para Thompson ${ }^{9}$, a compreensão das mensagens é um processo de entendimento e reentendimento de si mesmo, de autoinformação e autorreflexão. Carrega, assim, um potencial para a crítica e a autocrítica, mesmo que seja determinado e incompleto. Tal processo envolve compreensão, compartilhamento e conhecimentos próprios.

É nesse quadro referencial que se inscreve a abordagem dialógica da comunicação e saúde, fundada na compreensão de que a comunicação é um processo de negociação de sentidos, permeado por múltiplas mediações ${ }^{10}$. Nesse processo, a construção discursiva se realiza de forma dinâmica e desigual. Por isso, olhar os sujeitos-receptores nos espaços contraditórios de negociação e de busca de sentidos implica em olhá-los em situações e condições, como define Sousa ${ }^{11}$.

Os adolescentes participantes foram, portanto, considerados em suas capacidades de articulação de informações e de construção de conhecimento a partir de suas redes de sentidos. $\mathrm{O}$ estudo concentrou-se nesta perspectiva reflexiva, não tendo a intenção de verificar a conversão em prática pelos participantes de orientações sobre cuidados à saúde presentes nas narrativas jornalísticas analisadas. Deu particular atenção ao cotidiano desses adolescentes que convivem com situações discriminatórias pelo fato de residirem em uma periferia, agravadas quando se trata de populações jovens ${ }^{12}$.

\section{Métodos}

A análise está inserida em uma investigação ${ }^{13}$ que combinou técnicas de observação direta e indireta: descrição densa dos contextos, aplicação de questionário e reflexão em grupos. Para atender ao objetivo deste artigo, foram privilegiados os resultados obtidos com base no instrumento de grupos de discussão, técnica que busca observar os processos interativos e discursivos dos sujeitos de pesquisa. Seguindo esta linha, o pesquisador não conduz a dinâmica, mas propõe um tema como ponto de partida, estimulando o diálogo entre os participantes, que podem fazer associações com outros assuntos, não previstos, redirecionando o debate ${ }^{14}$.

As atividades desenvolveram-se em três grupos, sendo um deles composto por estudantes de uma escola pública municipal e os demais por participantes de projetos de duas organizações sociais. A escolha das instituições deveu-se a três razões: estarem situadas na Maré, abrigarem indivíduos na faixa etária definida e oferecerem condições para a realização das atividades. A pesquisa contou com 33 participantes, quase todos alunos do $9^{\circ}$ ano do Ensino Fundamental, apenas três cursavam séries anteriores. Os critérios de inclusão foram: ter entre 14 e 16 anos, residir no território e desejar participar da pesquisa. Buscou-se ainda equilíbrio de gênero. As atividades foram realizadas entre dezembro de 2012 e junho de 2013. O estudo foi aprovado pelo Comitê de Ética em Pesquisa da Escola Politécnica de Saúde Joaquim Venâncio, da Fundação Oswaldo Cruz.

O grupo 1 teve seis encontros e os grupos 2 e 3 tiveram cinco. Os dados analisados neste artigo foram coletados primordialmente nos dois encontros finais de cada grupo, nos quais as discussões abordaram produtos jornalísticos sobre cuidado e risco à saúde. Tais materiais foram selecionados pela pesquisadora com base no mapeamento feito nos encontros anteriores para identificar: a) quais eram os veículos jornalísticos acessados pelos participantes da pesquisa; b) quais eram os assuntos relacionados por eles à temática do cuidado e risco à saúde. Ou seja, a pesquisadora apresentou a cada grupo textos e vídeos extraídos de meios jornalísticos em que os participantes informaram acessar e que tratavam de temas associados por eles às noções de cuidado e risco. Os materiais foram submetidos à apreciação dos participantes para que escolhessem quais preferiam discutir. Por este motivo, e em respeito à diversidade apontada nos encontros anteriores, os grupos analisaram materiais distintos.

Cada grupo refletiu sobre no mínimo dois e no máximo quatro produtos jornalísticos. Neste artigo são apresentadas as discussões acerca de três produtos, um por grupo. De acordo com a orientação teórico-metodológica do estudo, a dinâmica da discussão é essencial para a construção de sentidos. Isto implica na análise dos diálogos em seu contexto, respeitando sua cronologia. As transcrições de trechos dos diálogos (gravados em áudio) adiante seguem essa premissa. Para preservar a identidade dos participantes, todos os nomes citados são fictícios. 
A análise dos dados, em consonância com a metodologia da pesquisa, foi construída ao longo do acompanhamento do processo reflexivo dos participantes no contexto das discussões nos grupos. Ao final das atividades, os adolescentes foram convidados a fazer uma avaliação das reflexões em seus grupos, que foi incorporada aos resultados do estudo.

\section{A camisinha onipresente e o "lado negativo" das matérias}

Um dos conteúdos analisados pelos participantes do grupo 1 foi a reportagem "Sexo na adolescência: 73\% dos jovens não usam camisinha na primeira transa", publicada na editoria de saúde e ciência do jornal Extra e veiculada no site Extra Online ${ }^{15}$. A seleção desse material para análise deveu-se ao fato de a temática da prevenção a infecções sexualmente transmissíveis (ISTs) ter sido destacada pelos participantes em encontro realizado anteriormente, que abordou os sentidos de saúde, cuidado e risco para eles. Seguindo o mesmo critério explicitado acima, a reportagem do jornal Extra foi escolhida por ter sido este um dos veículos jornalísticos citados por participantes do grupo no encontro no qual informaram quais os meios de comunicação eram acessados por eles.

O título cita os resultados de uma pesquisa realizada pela Universidade Federal de São Paulo (Unifesp) com o laboratório Bayer sobre uso de preservativos por jovens. Com foco na prevenção contra o papilomavírus humano (HPV), o texto informava que o Rio de Janeiro seria o primeiro estado brasileiro a oferecer doses da vacina, destinadas a meninas de 9 a 11 anos. A notícia mencionava a reação dos pais fluminenses como um possível desafio na implantação da imunização.

O início da discussão foi marcado pelo comentário de um participante que causou risos ao grupo. Ele demonstrou surpresa e desapontamento com a informação sobre a faixa etária restrita da vacinação contra o HPV no estado, e retrucou: Então, vou morrer virgem (Guilherme). $\mathrm{Na}$ sequência, a justificativa de que a vacina teria maior eficácia para quem ainda não iniciou a vida sexual provocou questionamentos de adolescentes, que deram exemplos de pessoas conhecidas não enquadradas nessa classificação.

A gente conhece pessoas de 20 anos que são virgens ainda. Com esse dado, eles acabam insinuando que as pessoas são virgens até os 11 anos; depois não precisa tomar vacina porque já se perdeu. Isto é bem chato, né? (Guilherme)
[Vários concordam.]

Tem gente velha que é virgem. (Guilherme)

A minha irmã tem 20 anos e é virgem. (Vitor)

Aí! (Luciano)

Aí ela pode pegar a doença porque não tem mais 11 anos? (Guilherme)

Ela nunca namorou. (Vitor)

Tudo bem, mas ela não pode agora tomar vacina. Aí no primeiro... [pausa] ela pega a doença. Como ela vai prevenir? (Nicole)

É uma coisa assim: até 11 anos é virgem; depois já não presta mais... (risos). (Guilherme)

O diálogo guarda correspondência com a polêmica surgida em 2014, no início da vacinação nacional contra o HPV, o que levou a comunicação governamental a rever a campanha, incorporando questões levantadas por usuários do Sistema Único de Saúde ${ }^{16}$. Ao envolver aspectos de ordem moral, como a virgindade, e questionamentos de decisões da estratégia de vacinação, o episódio, assim como a crítica dos participantes da pesquisa, indicam a importância de uma escuta ampliada para a garantia dos direitos à saúde e à comunicação.

Alguns participantes revelaram desconhecimento sobre o HPV. Houve quem confundisse inicialmente a sigla com HIV, o vírus da imunodeficiência humana, sobre o qual todos tinham informações. Questionados a respeito do que consideraram mais interessante na matéria e o que menos gostaram, foi mencionado o fato de o texto jornalístico apresentar apenas a sigla, e não o nome do vírus, como uma falha de comunicação. Contudo, avaliaram positivamente a possibilidade de acessar informações novas para eles e a clareza do texto, de fácil compreensão.

A crítica mais contundente em relação ao texto, embora não consensual, referiu-se à citação do percentual de adolescentes que não usariam preservativo na primeira relação sexual sem incluir informações sobre o universo dos pesquisados, seja o número absoluto de entrevistados, a localização geográfica ou a descrição do perfil da amostra. Esta omissão teria impacto sobre a credibilidade da matéria, conforme apontam as falas a seguir, ainda que houvesse opinião divergente.

Essa é uma fonte em que eu não acredito, porque é irrelevante dizer que $73 \%$ dos adolescentes na primeira transa não usam camisinha. (Guilherme).

Eu não acho. (Daniela).

Depende dos jovens que [eles] pesquisaram, se as pessoas pesquisadas namoram, têm alguma relação com religião ou ao costume familiar. Achei superjogado, né? (Guilherme) 
Isso é errado. Acho que deveriam ter colocado, tipo, entre dez ou vinte pessoas... (Mariana)

Melhor do que jogar assim: 73\%. (Verônica)

E $73 \%$ envolvem todos os jovens? (Guilherme)

Por exemplo, se ele pesquisou $10 \%$ da população do Rio de Janeiro. Começou com 100 mil, depois ficou entre 100. Dá um número elevado, mas se pesquisar todos, vai dar um número bem diferente. (Vitor)

A credibilidade da pesquisa também foi posta em questão por um adolescente, ao supor uma resposta "inventada" por algum entrevistado. Eu posso falar 'usei' ou 'não usei' sem nunca ter feito sexo (Guilherme). As falas revelam uma dupla desconfiança tanto no trabalho jornalístico quanto no trabalho de pesquisadores. Em primeiro lugar, ao ressaltarem a omissão de dados no texto sobre os números absolutos da pesquisa, os participantes põem em causa o fazer jornalístico, o que inclui a relação entre repórter e sua fonte científica. Em segundo, é posta em xeque a veracidade dos dados de pesquisa, envolvendo a atividade de pesquisa e, de modo especial, a relação entre pesquisador e entrevistado.

O debate suscitou uma reflexão a respeito da recorrente menção ao uso de preservativo como única possibilidade de realização do ato sexual. Destacaram-se: a carência de informações (na matéria) sobre outras formas de prevenção à gravidez e a ISTs; e a percepção de que a narrativa assume uma perspectiva negativa ao abordar o tema.

Por que não podem fazer sexo sem camisinha? Podem ter feito exames e visto que a mulher nem o parceiro têm alguma doença e que não há motivo para usar camisinha. Depende disto: se a pessoa quis experimentar sem camisinha ou se o casal não tem risco a trazer e se a menina se previne do não uso da camisinha. Sei lá, toma remédio no dia seguinte, tem DIU, anel, entendeu? (Guilherme)

Você está levantando que existem outros métodos que não... (pesquisadora)

Que não precisam da camisinha em si. Então, são $73 \%$ dos jovens, mas as mulheres pesquisadas têm algum outro método contraceptivo? Os parceiros sabiam que tinha doença ou não sabiam que tinham doença? (Guilherme)

A matéria orienta para a necessidade de usar a camisinha sempre? (pesquisadora)

Sim. [meninas respondem juntas]

Fala de prevenção, que pode levar a uma gravidez de risco... (Daniela)

$\mathrm{Na}$ verdade, acho que ele não fala em usar camisinha. Acho que ele joga para o lado negativo para a gente ir para o positivo. Para falar: "Não, isso tá errado, para a gente ir para o certo." (Guilherme)

Ele fala que a camisinha salva 70 a $80 \%$, certo? Não é 100\%, mas é grande parte, já faz pensar. (Alex)

Por exemplo: se vocênão fizer isto, vai acontecer isso, isso e isso. Fala o lado negativo, como ele falou, e a gente vai para o lado positivo. (Vitor)

O que é o lado positivo? (pesquisadora)

Usar. (Nicole )

Usar a camisinha, sim. Mas vocês ouvem, em outros meios, outros lugares sobre esse assunto, não só em matérias e reportagens? (pesquisadora)

Sobre usar camisinha? É bem frequente, na escola... (Guilherme)

Palestras, então... (Vitor)

É uma coisa que as pessoas insistem bastante. É um assunto que não passa despercebido. (Guilherme)

Até comerciais simples falam sobre isto. (Mariana)

O diálogo revela que à frequência com a qual ouvem ou leem informações como as descritas acima segue-se o questionamento. Mas não se esgota nele. $\mathrm{Na}$ fala Acho que ele joga para o lado negativo para a gente ir para o positivo, Guilherme apresenta sua leitura sobre uma estratégia possível do material de comunicação, o que permite outras contribuições dos colegas.

De acordo com os participantes desse grupo, quando têm dúvidas e/ou interesse de saber mais sobre um assunto, buscam confirmar as informações contidas nas reportagens. A fonte para confirmação dependeria do assunto, classificados em três tipos: íntimos, globais e sobre a comunidade. Para saber mais a respeito de assuntos íntimos, o caminho seria buscar um meio de comunicação ou "uma pessoa segura"; sobre temas globais, tentariam se informar "com alguém que entende muito sobre o assunto"; e acerca de acontecimentos no território onde vivem, acessariam as redes sociais virtuais. Esse acionamento de suas redes de sentidos após a recepção de conteúdo noticioso é a circulação, no sentido definido por Braga ${ }^{17}$ : aquilo que nos orienta em uma análise de valores simbólicos.

\section{Gravidez 'antes da hora' e a vida cotidiana}

A reportagem "Campanha polêmica contra gravidez na adolescência gera debate nos EUA"18, veiculada no Jornal Nacional (TV Globo), foi analisada pelos participantes do segundo grupo de adolescentes, seguindo o mesmo processo de seleção do primeiro grupo. A matéria aborda- 
va a repercussão de uma campanha promovida pela prefeitura de Nova York que afixou cartazes de conteúdo considerado agressivo em áreas de grande circulação da população-alvo. No vídeo, são mostrados dois pôsteres, ambos usando como recurso o que seria a fala de bebês filhos de adolescentes: Honestamente, mamãe, papai não deve ficar com você. E o que vai acontecer comigo? Você está pronta para criar um filho sozinha? (cartaz 1). O risco de eu não completar o Ensino Médio é duas vezes maior porque nasci de uma mãe adolescente. (cartaz 2)

O vídeo traz entrevistas com quatro pessoas, sendo uma representante da prefeitura e três críticos à campanha: um aposentado, uma jovem acompanhada da filha, gerada quando a mãe tinha 15 anos, e um psicólogo que atua em projetos de prevenção à gravidez em bairros pobres da cidade. $O$ repórter cita ainda o serviço, criado pela prefeitura, de troca de mensagens de texto, via telefone celular, no qual dois personagens que representam pais adolescentes trocam mensagens, e são chamados de perdedores e estúpidos. A agressividade da campanha foi destacada tanto por seus críticos quanto pela representante da prefeitura, que justifica a opção como estratégia para causar impacto.

Ao final da exibição da reportagem, adolescentes do grupo expressaram descontentamento, afirmando que não concordavam com o que viram. No decorrer do debate, demonstraram que o desagrado estava relacionado à abordagem da campanha, e não à reportagem em si. Estimulados a discutir o tema da matéria, os integrantes do grupo confrontaram as situações apresentadas no vídeo com aquelas vivenciadas em suas próprias famílias.

Eu entendi que uma pessoa grávida, na grande maioria das vezes, o pai da criança não fica com a pessoa. (Paula)

Que as meninas novas estão tendo filho cedo. (Carol)

Mas isso é normal. (Manuela)

É nada. (Cecília)

Agora é normal, antes não era, não. (Carol)

Pior que é. Minha mãe me teve com 16 anos. Fala aí! (Daniel)

É, minha mãe teve meu irmão com 17. (Henrique)

Para mim, de 15 anos para baixo que não é normal. (Jessica)

O diálogo levanta questões importantes para o debate sobre políticas de prevenção/promoção de saúde, tais como: as razões pelas quais a gravidez na adolescência passou a ser considerada um problema de saúde pública; ou o contexto em que a gravidez na adolescência passa a ser considerada de risco, com base em justificativas sobre a incompletude do desenvolvimento do corpo, quando as mães, avós e bisavós desses adolescentes puderam ter filhos aos 15 anos ou antes, sem problemas adicionais aos de uma gestação em mulheres adultas.

Não estão em discussão as preocupações com o futuro da adolescente grávida, que muitas vezes precisa abrir mão dos estudos para cuidar do filho, ou ingressar antecipadamente no mercado de trabalho para obter recursos ao sustento da criança. O que se põe em discussão são os argumentos desses discursos e a incapacidade de relativizá-los.

Brandão ${ }^{19}$ observa que tal enquadramento é feito de forma recorrente com relação a jovens de diferentes classes sociais. Parir antes dos 19 anos, décadas atrás não se constituía assunto de ordem pública”. A autora ressalta que o discurso "alarmista" e "moralizante" desconsidera aspectos importantes, a exemplo da chegada desses bebês à família como mediadores de afeto.

O verbo "prevenir" foi mencionado por dois adolescentes. Seguindo o caminho de diálogo apontado por eles, a pesquisadora perguntou se já tinham visto alguma campanha de prevenção à gravidez em meios de comunicação. Ninguém fez referência aos meios, em um primeiro momento e, mesmo após a reformulação da pergunta, citando especificamente as notícias, as respostas foram breves:

Às vezes. (Manuela)

Já. (Cecília)

No entanto, os participantes do grupo associaram imediatamente as "campanhas de prevenção à gravidez" ao posto de saúde, que havia sido mencionado, em encontro anterior, como fonte de informação. As intervenções reportaram à distribuição farta de preservativos "no postinho" e também "na rua". A discussão prosseguiu sobre o não uso da camisinha, trazendo à tona o argumento da frequência de acesso a informações sobre prevenção, também acionado pelo grupo 1, mas em abordagem diversa.

Nos diálogos paralelos apareceu a contradição entre o acesso - à informação e ao artefato material e simbólico da prevenção - e o cotidiano daqueles que são alvo das campanhas: "Ninguém usa", disse uma participante, imediatamente seguida por um colega. A assertiva remete ao juízo e/ou à expectativa de que esta seja a prática, embora a generalização ("ninguém") não inclua necessariamente os participantes. Citaram práticas relatadas por pessoas conhecidas. 
Na sequência da discussão, houve um questionamento sobre a utilidade de conteúdos, não necessariamente jornalísticos, sobre prevenção. As falas elucidam sobre os limites das intervenções comunicacionais que visam a mudança de atitude dos adolescentes, tanto no que se refere aos cuidados com a saúde quanto no planejamento de seu futuro. Registra-se, ainda, o predomínio de vozes femininas em alguns momentos da dinâmica, o que nos traz pistas sobre um posicionamento de gênero na comunicação sobre a prevenção da gravidez.

Ultimamente estão falando muito sobre isto. Isso já é normal. Prevenção existe. Todo mundo já sabe que existe. (Paula)

Hoje em dia, a coisa mais fácil é isto. A pessoa tem filho porque quer. (Carol)

Acho interessante para quem não sabe sobre isto, mas acho às vezes uma perda de tempo. Quem já sabe e não quer aprender...(Paula)

Acho que as pessoas hoje em dia ficam grávidas porque querem. Tem muita coisa para prevenir! Tem remédio, tem camisinha...(Carol)

A linguagem usada na campanha gerou falas repetidas, indignadas, que voltaram à cena no final da discussão, de forma a ressaltar o vínculo com a vida cotidiana dos participantes.

Nada a ver aquele cartaz que tem neném chorando. É..."Tenho problema mental porque minha mãe me criou, me fez na adolescência". Nada a ver! Eu achei aquilo nada a ver. (Manuela)

Eu não acho preconceituosa. Mas eu até concordo um pouco com ele. Para quem realmente não conhece, não sabe dessas coisas, até que é bom, mas da forma como eles falaram ali, parece até que se teve filho adolescente é pecado (Paula).

Chamar de imbecil...(André)

Destaca-se novamente o caráter moral implícito na campanha, que define valores desejáveis de conduta para adolescentes pobres, desconsiderando contextos e culpabilizando quem engravidou "antes da hora". O diálogo mostra ainda a capacidade dos participantes do grupo de relativizarem as informações acessadas, com o acionamento de suas redes discursivas. Soma-se a isso, o discernimento de que a matéria teria um posicionamento crítico à campanha.

\section{'Ninguém quer saber de nada da favela!'}

A escolha da reportagem intitulada "Mortes e revolta na Maré" ${ }^{20}$ manchete do jornal O Dia, para discussão no terceiro grupo teve motivação tripla. A primeira delas deveu-se ao destaque dado pelos participantes a questões relacionadas à violência, que emergiram no encontro no qual o grupo discutiu as noções sobre cuidado e risco à saúde. $\mathrm{O}$ medo de ser baleado(a) foi um dos registros expressos naquele debate. $\mathrm{O}$ segundo motivo para a escolha da reportagem foi o fato de a ação das forças de segurança na Maré ter ocorrido na véspera do encontro com os adolescentes. Além dos dez mortos (incluindo um policial) e de feridos, casas foram invadidas e muitos moradores passaram a noite ao relento, impedidos de voltar para casa. O tiroteio durou toda a noite e as operações continuaram no dia seguinte. As escolas não tiveram aula. A terceira razão foi a repercussão do acontecimento nos meios de comunicação. A reportagem do jornal O Dia ocupou quatro páginas, incluindo as centrais, com sete retrancas (matérias coordenadas) e um artigo assinado por dois dirigentes de organizações sociais da favela. Acrescenta-se a essas razões o fato de o jornal O Dia ter sido citado por participantes do grupo, em encontro anterior, como um dos meios aos quais tinham acesso, por ser hábito de leitura de familiares.

A discussão foi iniciada com pergunta sobre qual seria o tema central da matéria. O abuso de autoridade, respondeu prontamente Luís. Seguiram-se várias referências à usurpação de poder, identificado na instância governamental e nos agentes que instrumentalizam o desrespeito aos direitos humanos e civis dos moradores da favela.

Eles estão matando, e não prendendo. (Sabrina)

$\mathrm{E}$ isso tem a ver com o quê, para vocês? (Pesquisadora)

Com a violência. (Sabrina)

[No texto,] falam da diferença de atitude da polícia na favela e em outros lugares. (Pesquisadora)

É diferente como tratam a pessoa na favela. Se o bairro tem dinheiro, tratam muito bem. Aqui, não. Abrem a porta de qualquer um, chegam sem mandado. Lá não, tem que ter mandado. (Sabrina)

Eles são muito ignorantes pro meu gosto. (Stefany)

Vocês viram que essa matéria, com várias pessoas entrevistadas, não traz uma opinião só. Tem opiniões diferentes, né? (Pesquisadora)

Eu acho que tem que mudar. Só porque a gente abre a porta de cara feia, ele [policial] vem revistar a casa. Ficam olhando o celular da pessoa na rua... (Stefany)

Embora as falas tenham trazido o repúdio das participantes em relação a práticas recorrentes das forças de segurança na favela e a clareza quanto aos procedimentos legais que deveriam ser adotados antes de uma abordagem ou de 
qualquer ação repressiva, o grupo conteve-se nesta discussão. Uma provável razão para isso surgiu na continuidade do debate, quando se buscou saber se concordavam com a forma com que a matéria foi feita.

Não está completa. Não está falando "Ah, os policiais são inocentes", mas pende mais pro lado do governo. (Nicholas)

Eu não ouvi falar que os moradores...(Sabrina)

Eu não ouvi falar o nome de quem fez a matéria, só o policial... Não apareceu o nome de uma pessoa que trabalha na favela, só...(Stefany)

Mas falaram! Interpreta o texto! (Luís)

O jornal não falou dos moradores, dos que morreram na favela. (Sabrina)

[Várias falas simultâneas]

Não ouviram as famílias dos moradores. (Sabrina)

Nem pra dar um apoio aos familiares das vitimas. (Luís)

Ninguém quer saber de nada da favela! (Sabrina)

Por que vocês acham que não ouviram as pessoas da favela? Tem três pessoas de organizações sociais da Maré. Vocês acham que eles estão falando em nome de quem? (Pesquisadora)

Da Maré. (Luís)

Da população da Maré. (Sabrina)

$\mathrm{Na}$ fala deles, eles estão chamando a atenção para quê? (Pesquisadora)

Para defender, para... (Sabrina)

Para a crueldade dos policiais. Chegam atirando. (Luís)

Mas por que vocês acham que, fora eles, não tem outras pessoas falando da comunidade? (Pesquisadora)

Porque ninguém põe pra fora, não.(Sabrina)

A transcrição sequencial das falas busca trazer sua dimensão contextual. Destacam-se, inicialmente, as intervenções de Stefany e Luís sobre a inclusão dos nomes de quem fez a matéria e dos moradores. Ao divergir da colega, ele sugere que ela interprete o texto. O convite à releitura da matéria provocou o grupo no esforço reflexivo de afastamento daquele cenário de violência.

Por que a matéria penderia mais para o lado do governo se há mais espaço ocupado pelo questionamento à ação policial, incluindo a página central, do que aquele destinado às fontes dos órgãos governamentais? O lamento de Luís (Nem pra dar um apoio aos familiares das vítimas) e o de Sabrina (Ninguém quer saber de nada da favela!) nos dão uma pista para entender por que a manchete e quatro páginas em um jornal foram insuficientes para denunciar a violência sofrida.
O desejo pela presença de vozes dos moradores na reportagem é justificado pela própria adolescente que expressou a sua ausência. A dificuldade de pôr para fora se explica pela imposição do silêncio para aqueles que convivem com violência armada na favela. Esse dispositivo de defesa dos moradores (o silêncio), no entanto, tem natureza e a extensão variáveis, conforme observam Machado da Silva e Leite ${ }^{21}$, assim como as formas de lidar com as condutas violentas.

Além dessas vozes dos moradores, quando perguntados sobre o que teriam sentido mais falta na reportagem, três participantes referiramse a informações sobre a ocupação da favela. A maioria afirmou que teria interesse em ler a matéria. E sobre a confiança nas informações, dois participantes afirmaram:

Eu confiaria em algumas coisas. (Sabrina)

Não confio $100 \%$. (Luís)

As reticências quanto à confiabilidade depositada no produto jornalístico em análise apontaram mais para o exercício da dúvida do que para a rejeição daquele conteúdo. Não houve manifestações de discordância quanto a alguma informação específica, apresentada no texto jornalístico. $\mathrm{O}$ fato de o acontecimento ser muito recente e próximo também deve ser considerado, tanto no sentido da memória da tragédia quanto da necessidade de terem mais tempo para refletirem sobre as informações acerca do episódio.

\section{Considerações finais}

A correlação entre o comportamento dos adolescentes e as informações que acessam têm sido objeto de investigações no campo da saúde, e não raras vezes a divulgação de resultados ocupa o noticiário. Em vez de mirar as práticas, este estudo buscou observar as reflexões suscitadas a partir do contato, direto ou indireto, com produtos jornalísticos de diferentes suportes sobre a temática recortada.

Nesta perspectiva, a pergunta da pesquisa teve como elemento central a apropriação, processo este extenso de conhecimento e autoconhecimento, conforme define Thompson ${ }^{22}$.O exercício de vislumbrar as formas de apropriação dos adolescentes de conteúdos jornalísticos que abordassem temas relativos ao cuidado de si e ao risco à saúde concentrou-se em analisar uma parte significativa desse processo, por meio das reflexões em grupo propiciadas no compartilhamento de informações, opiniões, dúvidas, inquietações e expectativas. 
O estudo propôs-se a olhar para seu objeto teórico e empírico à luz das contribuições do campo interdisciplinar da comunicação e saúde, com foco nas reflexões sobre aos processos de construção social de sentidos. A proposta metodológica creditou aos processos interacionais dos participantes dos grupos não apenas as respostas aos questionamentos iniciais da investigação, mas as revisões e reconstruções feitas por eles no decorrer dos encontros. Desta forma, buscou aproximar-se das dinâmicas que se estabelecem nos diálogos da vida cotidiana.

As discussões nos grupos sugerem uma intensa circulação, no cotidiano dos participantes, de narrativas jornalísticas sobre o cuidado e risco à saúde, gerando questionamentos diversos que ampliam o debate para a inserção política desses sujeitos como cidadãos. A análise apontou que essa presença do jornalismo não se dá sem críticas ao seu modus operandi, independentemente da confiabilidade no veículo. A crítica se estende a outros atores acionados como fontes das matérias/reportagens, sobretudo ao abordarem temas relacionados a condições de vulnerabilidade social.

Se a credibilidade é o principal capital simbólico do jornalismo, sustentado hoje, em grande medida, no manejo de fontes de informação, a confiabilidade das informações revela-se crucial para a compreensão dos processos de apropriação. Entre outras razões, ela permite a reconexão do sujeito ao seu tempo e à comunidade a qual pertence, além de possibilitar a tomada de decisões ${ }^{23}$.

Outro achado importante da pesquisa foi a saturação de informações sobre temas abordados nas matérias analisadas: a prevenção à gravidez e a infecções sexualmente transmissíveis; e a violência. Nos três grupos houve manifestações nesse sentido. A questão merece reflexão mais detida não apenas por formuladores de políticas públicas, mas também por profissionais de comunicação que atuam na produção de conteúdos sobre cuidado e risco à saúde. Tal esgotamento sugere ainda a necessidade de uma revisão das abordagens na promoção da saúde. Seguindo uma perspectiva dialógica da comunicação e saúde, as estratégias comunicacionais devem buscar estabelecer um debate público sobre um tema e permitir o acesso a informações de qualidade e suficientes para que a tomada de decisões das pessoas, além de ampliar a participação desses sujeitos nas políticas públicas de saúde ${ }^{24}$.

O exercício analítico indicou a potencialidade de estudos centrados na circulação de informações entre adolescentes e jovens sobre cuidado e risco à saúde, sobretudo aqueles que considerem o intercâmbio de múltiplas fontes referenciais, entre elas o jornalismo. Vislumbra, assim, o desenvolvimento de pesquisas que preencham a lacuna de estudos acerca da apropriação de narrativas sobre saúde por adolescentes e jovens em contextos de vulnerabilidade. 


\section{Referências}

1. Czeresnia D. O conceito de saúde e a diferença entre prevenção e promoção. In: Czeresnia D, Freitas CM, organizadores. Promoção de saúde: conceitos, reflexões, tendências. 2 ed. rev. ampl. Rio de Janeiro: Editora Fiocruz; 2009.

2. Vaz P, Pombo M, Fantinato M, Pecly G. O fator de risco na mídia. Interface (Botucatu) 2007; 11(21):145163.

3. Pais JM. Culturas juvenis. Lisboa: Imprensa NacionalCasa da Moeda; 1993.

4. Castiel LD, Sanz-Valero J, Vasconcellos-Silva PR. Das loucuras da razão ao sexo dos anjos: biopolitica, hiperprevenção, produtividade científica. Rio de Janeiro: Editora Fiocruz; 2011.

5. Reguillo R. Culturas juveniles: formas politicas del desencanto. Buenos Aires: Siglo Veinteuno Editores; 2013.

6. Freire Filho J. Retratos midiáticos da nova geração e a regulação do prazer juvenil. In: Borelli S, Freire Filho J, organizadores. Culturas juvenis no século XXI. São Paulo: Educ; 2008.

7. Sodré M. Antropológica do espelho: uma teoria da comunicação linear e em rede. Petrópolis: Vozes; 2002.

8. Martín-Barbero J. Dos meios às mediações: comunicação, cultura e hegemonia. $4^{\mathrm{a}}$ ed. Rio de Janeiro: Universidade Federal do Rio de Janeiro; 2006.

9. Thompson JB. Ideologia e cultura moderna: teoria social crítica da era dos meios de comunicação de massa. 6a ed. Petrópolis: Vozes, 1995.

10. Martín-Barbero J. Dos meios às mediações: comunicação, cultura e hegemonia. $4^{\mathrm{a}}$ ed. Rio de Janeiro: UFRJ; 2006.

11. Sousa MW. Recepção e comunicação: a busca do sujeito. In: Sousa, MW, organizador. Sujeito, o lado oculto do receptor. São Paulo: Brasiliense, 1995.

12. Novaes R. Os jovens de hoje: contextos, diferenças e trajetórias. In: Almeida, IM, Eugenio F, organizadores. Culturas jovens: novos mapas do afeto. Rio de Janeiro: Zahar; 2006

13. Lisboa MR. Cuidado, ser adolescente é arriscado: formas de apropriação de produtos jornalísticos sobre cuidado e risco à saúde por adolescentes da Maré [tese]. Rio de Janeiro: Fundação Oswaldo Cruz; 2014.

14. Weller W. Grupos de discussão na pesquisa com adolescentes e jovens: aportes teórico-metodológicos e análise de uma experiência com o método. Educação e Pesquisa 2006; 32 (2):241-260.

15. Sexo na adolescência: $73 \%$ dos jovens não usam camisinha na primeira transa. Extra Online [jornal]; 2012 Set 26. [acessado 2020 abr 20]. Disponível em: http:// extra.globo.com/noticias/saude-e-ciencia/sexo-naadolescencia-73-dos-jovens-nao-usam-camisinha-na -primeira-transa-6199418.html
16. Quevedo JP, Inácio M, Wieczorkievicz AM, Invernizzi N. A política de vacinação contra o HPV no Brasil: a comunicação pública oficial e midiática face à emergência de controvérsias. $R$ Tecnol Soc 2016; 12(24):126.

17. Braga JL A sociedade enfrenta sua mídia: dispositivos sociais de crítica midiática. São Paulo: Editora Paulus; 2006.

18. Campanha polêmica contra gravidez na adolescência gera debate nos EUA. Jornal Nacional TV Globo; 2013 mai 3. [acessado 2020 abr 20]. Disponível em: http:// g1.globo.com/jornal-nacional/noticia/2013/05/campanha-polemica-contra-gravidez-na-adolescenciagera-debate-nos-eua.html.

19. Brandão ER. Gravidez na adolescência nas camadas médias: um olhar alternativo. In: Almeida IM, Eugênio F, organizadoras. Culturas jovens: novos mapas do afeto. Rio de Janeiro: Zahar; 2006.

20. Mortes e revolta na Maré - Confronto entre policiais e traficantes, após arrastão, terminou em tragédia, com nove pessoas mortas: um sargento do Bope, três vítimas de balas perdidas e cinco acusados de ser bandidos. Moradores protestaram e tentaram fechar a Avenida Brasil. O Dia. versão impressa; 2013 Jun 26.

21. Silva LAM, Leite M. Violência, crime e polícia: o que os favelados dizem quando falam desses temas? Soc Estado 2007; 22(3):545-591.

22. Thompson JB. A mídia e a modernidade: uma teoria social da mídia. 11 a ed. Petrópolis: Vozes; 2009.

23. Karam FJC, Christofoletti R. Fundamentos jornalísticos para novos cenários éticos da informação. In: Silva G, Künsch DA, Kuschick CLBR, Albuquerque A, organizadores. Jornalismo contemporâneo: figurações, impasses e perspectivas. Salvador: EDUFBA, Brasília: Compós; 2011. p. 79-101.

24. Araújo IS. Comunicação e Saúde. In: Martins C, Stauffer AB, organizadoras. Educação e Saúde. Rio de Janeiro: Escola Politécnica de Saúde Joaquim Venâncio; 2007. p. 101-124.

Artigo apresentado em 28/05/2020

Aprovado em 09/04/2021

Versão final apresentada em 11/04/2021

Editores-chefes: Romeu Gomes, Antônio Augusto Moura da Silva 